\title{
Previsão de séries temporais financeiras: modelo baseado em redes neurais artificiais
}

\author{
Cássio Cristiano Thiele ${ }^{1}$ \\ André Gustavo Adami ${ }^{1}$
}

\begin{abstract}
Resumo: a projeção do comportamento das ações é de fundamental importância para investidores obterem bons retornos financeiros no mercado acionário. A possibilidade de previsão de valores futuros de uma série temporal financeira está baseada em uma das principais premissas da escola de análise técnica de ações: preços futuros são uma repetição de preços passados. Este artigo propõe a criação de um modelo previsor, baseado na combinação de redes neurais artificiais, para prever a tendência de movimentação do preço de um selecionado de ações. Dados históricos e de indicadores de análise técnica foram utilizados como entrada para o sistema, que realiza a previsão de tendência, de alta ou de baixa no preço, para um horizonte de um dia, o próximo dia da série temporal. O sistema previsor final alcançou uma taxa de acerto, que variou entre 55\% e 58\% para as três ações analisadas. Ao realizar uma simulação de investimento, observou-se que sua utilização possibilitaria a obtenção de lucros de $13 \%$ a $24 \%$, no período de um ano. Considerando que as ações analisadas tiveram quedas entre $15 \%$ e $30 \%$ nesse mesmo período, pode-se dizer que o sistema previsor apresentou um bom desempenho.
\end{abstract}

Palavras-chave: Combinação de redes neurais artificiais. Previsão de ações. Redes neurais artificiais.

\begin{abstract}
: stock market behavior prediction is of fundamental importance for investors to obtain good financial returns in the stock market. The ability to forecast future values of financial time series is based on one of the main premises of the school of technical stock analysis: future prices are a repetition of past prices. This paper proposes to develop a predictor model, based on the combination of Artificial Neural Network, to predict the price movement trend of a selected stock. Historical data and analysis techniques indicators were used as input to forecaster, that forecast trend, high or low in price, for a horizon of one day, that is, the next day in the time series. The trend forecast system achieved a hit rate ranging between 55\% and 58\% for the 3 analyzed stocks. When performing an investment simulation, we found that the system would return between $13 \%$ and $24 \%$ in profits over an 1-year period. Given that the stocks used in the experiments fell between $15 \%$ and $30 \%$ during the same period, it is possible to claim that the predictor system performed well.
\end{abstract}

Keywords: Artificial neural networks. Combination of expert systems. Stocks prediction.

\section{Introdução}

Com o advento da internet, no final dos anos 1990, foi instituído o pregão eletrônico, possibilitando aos investidores operar eletronicamente por intermédio dos sites das corretoras de valores. Essa possibilidade proporcionou maior facilidade de negociação, se comparado ao antigo sistema de pregão viva-voz, no qual as operações ocorriam fisicamente nos prédios das bolsas de valores [1]. Após essa mudança, o mercado de ações se popularizou, pois trata-se de um mercado bastante atrativo, que possibilita ao investidor a obtenção de lucros maiores, se comparados a muitos outros produtos do mercado financeiro.

No entanto, ganhar dinheiro com o investimento em ações não é uma tarefa fácil. O preço pelo qual uma ação é negociada em bolsa é fruto das condições de mercado (oferta e demanda) que refletem as condições

\footnotetext{
${ }^{1}$ Curso de Bacharelado em Ciência da Computação, UCS, Rua Francisco Getúlio Vargas, 1130 - Caxias do Sul (RS) - Brasil.

\{thiele.cassio@gmail.com, agadami@ucs.br\}
}

http://dx.doi.org/10.5335/rbca.v8i2.5638

Revista Brasileira de Computação Aplicada (ISSN 2176-6649), Passo Fundo, v. 8, n. 2, p. 113-128, jul. 2016113 
estruturais e comportamentais da economia do país e as específicas da empresa e do setor econômico em que ela atua [1]. Portanto, a projeção do preço das ações é bastante complexa e essa é uma tarefa necessária para reduzir o risco do investimento em ações.

Como formas de projeção do futuro preço das ações, pode-se destacar as duas principais: análise fundamentalista e análise técnica. A análise fundamentalista baseia-se nos resultados setoriais e específicos de cada empresa, dentro do contexto da economia nacional e internacional. Sua premissa básica é que o valor da ação está diretamente relacionado à capacidade de a empresa gerar lucros [1]. Já a análise técnica, é o estudo da ação no mercado, por meio do uso de gráficos, com o propósito de prever tendências futuras de movimentação dos preços. As premissas da análise técnica são: o mercado assimila fatos políticos, econônicos e psicológicos na formação do preço das ações, os preços se movem em tendências e os preços futuros são uma repetição dos preços passados [2]. Portanto, seguindo as premissas da análise técnica chega-se à conclusão de que uma boa análise técnica dispensa a pesquisa sobre os fundamentos da empresa, pois os gráficos são a soma de todos os conhecimentos, esperanças e expectativas sobre determinada ação [1].

A análise técnica tem como premissa olhar dados passados para prever futuros dados. Porém, o reconhecimento de padrões em uma grande quantidade de dados é complexo e pode ser muito demorado se realizado por humanos. Para tanto, podem ser desenvolvidos sistemas computacionais para o reconhecimento de padrões presentes nos dados. Esses sistemas adquirem conhecimentos em um processo de treinamento e depois os utilizam para resolver problemas similares.

Neste trabalho, propõe-se a criação de um sistema de previsão da tendência de movimentação dos preços de algumas ações de grande destaque na economia brasileira, de forma que o sistema indique se a tendência é de alta ou baixa para o dia seguinte. Para tanto, são utilizados os conceitos de análise técnica das ações, em que as informações referentes ao mercado de ações são analisadas na busca por um padrão de comportamento da movimentação dos preços. Essas informações utilizadas são dados de mercado, capturados quase que exclusivamente da BM\&FBovespa, e representam o resumo de negociação das ações, índices de mercado e outras informações consideradas relevantes para a formação do preço de uma ação em bolsa.

Este texto está estruturado de forma que na presente seção são apresentados conceitos introdutórios desse trabalho. Na Seção 2, são abordados aspectos gerais sobre a criação de sistemas de previsão de séries financeiras bem como serão comentadas algumas referências a trabalhos correlatos. Na Seção 3, é apresentada a proposta de solução para o problema de previsão de séries temporais financeiras. A Seção 4 detalha a metodologia utilizada no desenvolvimento desse trabalho. A Seção 5 descreve os experimentos realizados e os resultados alcançados. Por fim, na Seção 6, são apresentas as conclusões.

\section{Sistemas de previsão de séries financeiras}

Os sistemas previsores de séries financeiras podem ser tomados como um problema de reconhecimento de padrões. O reconhecimento de padrões pode ser definido como uma disciplina que tem por objetivo classificar objetos em um número de categorias ou classes, utilizando para tanto informações que possam auxiliar nessa classificação [3]. A classificação de objetos em determinada classe somente é possível se os objetos das classes se diferem uns dos outros por determinadas peculiaridades [4]. Dessa forma, o processo de criação de sistemas previsores pode ser dividido em duas etapas, a extração de características dos dados e a previsão propriamente dita.

\subsection{Extração das características}

A extração das características consiste na seleção das variáveis a serem utilizadas e na transformação sobre elas realizadas a fim de evidenciar suas características. A seleção das variáveis é uma tarefa muito importante e afeta fortemente o projeto de um classificador [5]. Em uma análise dos trabalhos correlatos com relação às variáveis selecionadas observa-se que as variáveis podem ser divididas em dois grupos: variáveis dependentes da ação a ser prevista e variáveis exógenas.

As variáveis dependentes correspondem ao resumo diário de negociação das ações em bolsa: preço de fechamento, preço de abertura, preço máximo, preço mínimo e volume negociado em um determinado dia. A série do preço de fechamento, que normalmente é a série que se deseja prever o futuro, sempre está entre os dados

Revista Brasileira de Computação Aplicada (ISSN 2176-6649), Passo Fundo, v. 8, n. 2, p. 113-128, jul. 2016114 
selecionados para o treinamento do modelo de previsão. Em alguns casos, o preço de fechamento é a única variável a ser considerada [6] [7] [8] [9]. As demais informações do resumo diário (preço de abertura, máximo, mínimo e volume negociado) estão frequentemente entre as variáveis selecionadas [10] [11] [12] [13] [14] [15] [16].

As variáveis exógenas são independentes daquela que se busca fazer a previsão, não possuem uma ligação direta com o ativo a ser previsto. As variáveis exógenas são escolhidas por apresentarem alguma possível relação de influência na formação do preço do ativo. Uma das variáveis frequentemente selecionada é a taxa de câmbio de moedas, como em [11], das quais foram selecionadas a cotação do euro e do dólar em relação ao real, em [13], cujos autores utilizaram a cotação do dólar em relação à moeda local na Turquia, a lira turca. Outra variável exógena, por vezes selecionada, são os índices de bolsas de valores, que são um indicador de desempenho médio de um conjunto de ações, de um país ou de determinado setor econômico, como utilizado em [11].

A outra etapa da extração das características é a aplicação de operações matemáticas sobre o conjunto original dos dados para transformar as variáveis, criando outros dados que sejam mais representativos no processo de classificação. A transformação de variáveis também pode ser útil na eliminação de informações redundantes ou irrelevantes, que não contribuem para o processo de classificação [17]. Dentre as operações de transformação aplicadas em trabalhos correlacionados, pode-se destacar o uso de taxa de variação [6] [18], médias móveis exponenciais [6] [19] e médias móveis simples [15] [20].

\subsection{Previsão}

Para contruir sistemas previsores existem diversos métodos estatísticos que podem auxiliar nessa tarefa, como os modelos autorregressivos, de médias móveis e modelos ARIMA [21]. Além desses, técnicas de inteligência computacional, tais como redes neurais artificiais e máquinas de vetor de suporte, proporcionam a criação de metodologias avançadas de previsão [6] [22] [13]. Em uma análise dos trabalhos relacionados, nota-se que as escolhas dos modelos computacionais de previsão, em sua grande maioria, recaem sobre a técnica de redes neurais artificiais.

\section{Sistema proposto}

Na concepção de sistemas que buscam a previsão de séries temporais financeiras, a técnica que mais se destaca é a de redes neurais artificiais. Esse destaque se dá pelo fato de que as RNAs têm uma grande capacidade de generalização, sendo eficientes na previsão de séries temporais financeiras [21].

Porém, essa é uma tarefa complexa devido à grande quantidade de informações que envolve. Um conceito fundamental que pode auxiliar na resolução de tarefas complexas é o de máquinas de comitê. Essas máquinas tem como premissa central que a resolução de uma tarefa complexa pode ser obtida por meio da sua divisão em subtarefas, delegando cada uma delas a diferentes sistemas. Os resultados de cada sistema são combinados gerando uma solução supostamente melhor do que qualquer solução alcançável por um sistema atuando isoladamente [23].

Nesse contexto, é proposto um modelo de combinação de RNAs como mostra a Figura 1. Esse sistema foi modelado por meio de três RNAs, em que a primeira utiliza como dados de entrada as variáveis dependentes do ativo, a segunda utiliza variáveis exógenas e indicadores de análise técnica obtidos por meio de uma transformação nas variáveis, e a terceira, uma RNA de fusão, que utiliza como dados de entrada as saídas das duas primeiras RNAs.

Inicialmente, a primeira e a segunda RNAs são treinadas individualmente para fazer a previsão das ações, gerando dois sistemas que "aprenderam"o padrão de relação entre os dados de entrada que utilizam e a movimentação do preço no dia seguinte. Após o término do treinamento das primeiras RNAs é que se inicia o treinamento da RNA de fusão, com o objetivo de melhorar a previsão obtida pelas primeiras, agregando o conhecimento de ambas as RNAs anteriores.

\subsection{Seleção das séries financeiras}

Séries temporais financeiras são um conjunto de dados históricos que indicam a cotação dos mais diversos ativos no mercado financeiro ao longo do tempo. Neste trabalho foram selecionadas séries temporais de ações para

Revista Brasileira de Computação Aplicada (ISSN 2176-6649), Passo Fundo, v. 8, n. 2, p. 113-128, jul. 2016115 


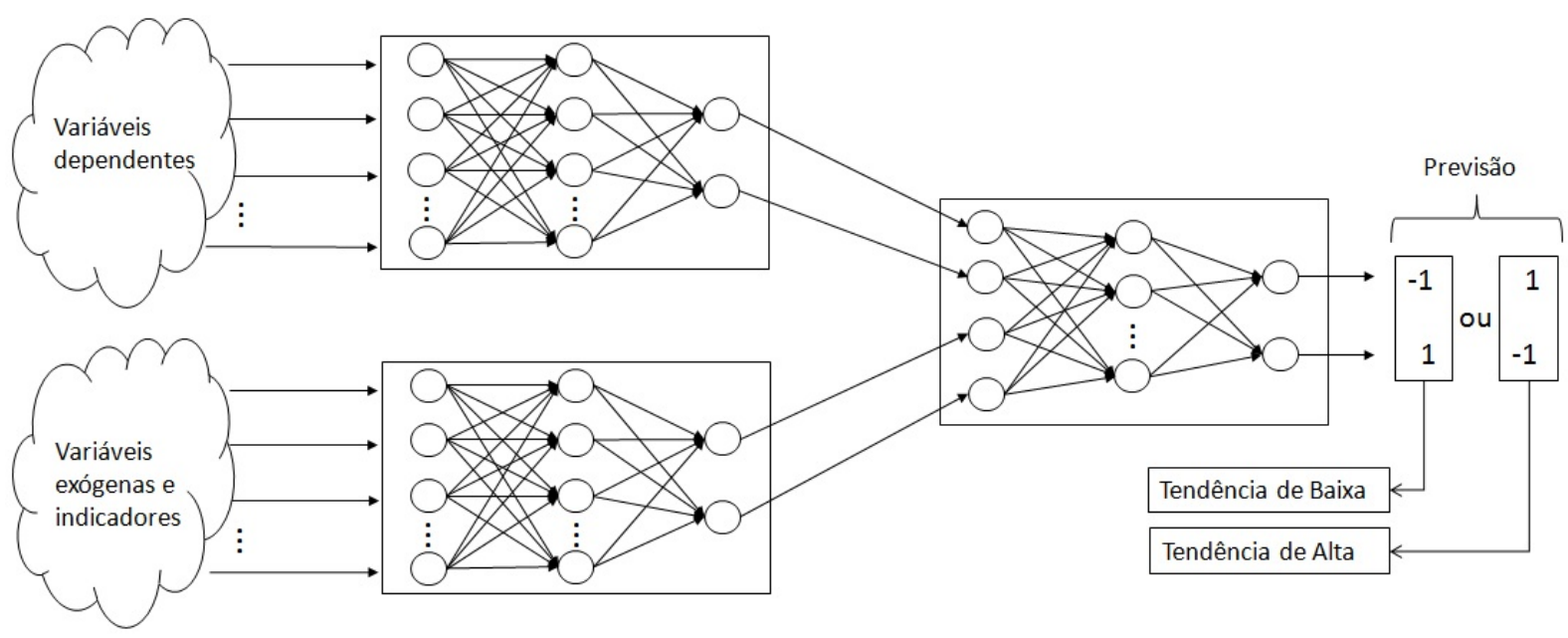

Fonte: elaborada pelos autores com base em dados da pesquisa.

análise. Os critérios para seleção das ações foram:

- Ações devem apresentar alta liquidez no mercado acionário, pois a liquidez reflete a facilidade com que determinado ativo é negociado, sem prejuízo de valor.

- Ações devem pertencer a empresas e setores de atuação diferenciados. É utilizada a setorização da bolsa de valores BM\&FBovespa para fins de comparação.

- Ações devem estar sendo negociadas na BM\&FBovespa desde $1^{\circ}$ de janeiro de 2011.

Seguindo os critérios definidos, e limitando o número de ações em três, as selecionadas foram: ITUB4, da empresa Itaú Unibanco, atuante no setor financeiro, PETR4, da empresa Petrobrás, que atua no segmento de gás e petróleo, e a VALE5, da empresa Vale, do setor de materiais básicos.

\subsection{Extração das características}

As variáveis selecionadas são separadas em dois grupos: variáveis dependentes dos ativos e variáveis exógenas. As variáveis dependentes selecionadas são todas as informações que resumem um dia de negociação em bolsa: preço de abertura, preço de fechamento, preço máximo, preço mínimo e volume negociado. As variáveis exógenas selecionadas são: cotação do dólar, índice de mercado IBovespa e o índice setorial de cada ação. Para as ações ITUB4 e VALE5 a BM\&FBovespa disponibiliza um índice setorial, o índice financeiro e o índice de materiais básicos, respectivamente. No entanto, a BM\&FBovespa não disponibiliza um índice setorial do setor de gás e petróleo, por esse motivo, a cotação do barril de petróleo Brent, que é uma importante informação do setor, foi utilizada em substituição ao índice setorial.

Além dessas informações selecionadas, foram criados novos dados a partir de transformações da variável dependente preço de fechamento, os indicadores de análise técnica Bandas de Bollinger (BB), Convergência e Divergência da Média Móvel (MACD) e Intersecção de Médias Móveis (MMS). Todos os três indicadores são gerados a partir do cálculo de médias móveis simples, médias móveis exponenciais e operações matemáticas.

\subsection{Configuração das redes neurais artificiais}

RNAs são um sistema de processamento de informações paralelo e distribuído, constituído de unidades de processamento simples, com objetivo de armazenar conhecimentos adquiridos por meio de experiências e torná-los 
disponíveis para uso [23]. As RNAs se assemelham ao cérebro humano, pois ambos adquirem conhecimentos por meio de processos de aprendizagem. As conexões entre os neurônios artificiais, conhecidas como sinapses, têm associados a elas os pesos sinápticos, que são os responsáveis por armazenar os conhecimentos adquiridos pela RNA.

As RNAs possuem grande capacidade de generalização e são bem adequadas para tarefas de classificação, cujo objetivo é definir à qual classe pertence determinada entrada, identificando padrões existentes nos dados que permitem fazer a classificação [24]. Com isso exposto, pode-se concluir que o uso de RNAs para previsão de tendência de séries financeiras é adequado, pois trata-se de uma tarefa de reconhecimento de padrões e classificação quanto à tendência de movimentação do preço.

O perceptron é um modelo de RNA, que consiste de uma única camada de processamento e é capaz de solucionar problemas de classificação de padrões linearmente separáveis. Quando os problemas são do tipo nãolinear o uso de múltiplas camadas de perceptrons deve ser aplicado. Nesse caso, os neurônios da camada posterior recebem as saídas dos neurônios da camada anterior como suas entradas. Essas RNAs são conhecidas na literatura como MLP (que vem do inglês Multilayer Perceptron e significa Perceptron de Múltiplas Camadas).

Quanto à topologia da RNA-MLP, o número de camadas escondidas bem como o número de neurônios nessas camadas são definidos de forma empírica. RNAs-MLP com uma camada escondida são capazes de gerar funções de aproximação universal muito precisas e satisfatórias [25]. Quanto ao número de neurônios integrantes da camada escondida, esses são definidos a partir de testes.

Um dos algoritmos mais utilizados no treinamento de RNAs-MLP é o algoritmo de retropropagação, mais conhecido na literatura como backpropagation [6] [8] [10] [13] [16]. O algoritmo backpropagation é baseado na regra de aprendizagem por correção de erro e consiste na aplicação de dois passos através das diferentes camadas da RNA: um passo à frente, a propagação, e um passo atrás, a retropropagação.

Na propagação, um vetor de entrada é aplicado aos neurônios da primeira camada e esses valores são propagados pela RNA até produzirem um conjunto de saídas na última camada. Inicialmente os pesos sinápticos são atribuídos de forma aleatória.

A partir dos dados de saída obtidos, e conhecendo-se os dados desejados, é calculado o erro dos neurônios da camada de saída. Esse sinal de erro é propagado para trás através da rede na direção contrária das conexões sinápticas, realizando o ajuste dos pesos sinápticos.

O treinamento da RNA-MLP por meio do algoritmo backpropagation consiste em realizar o processo de propagação, seguido da retropropagação, para um conjunto de diferentes exemplos de treinamento, por diversas iterações, até que o critério de parada seja satisfeito [23]. O critério de parada estabelecido é o da variação mínima do erro quadrático médio, considerando que o algoritmo converge quando a taxa absoluta de variação do erro for suficientemente pequena, no caso menor que 0,0001 . Caso o algoritmo não convirja até um dado limite de iterações o treinamento é encerrado.

\subsection{Métricas de avaliação de desempenho}

Após o treinamento ser realizado utilizando o conjunto de amostras de treinamento, o sistema é testado com conjunto de amostras de testes, para verificar se o sistema previsor aprendeu um padrão generalizado. As métricas de avaliação consideram o acerto ou erro da previsão de movimentação do preço. Para tanto foram selecionadas e definidas as métricas taxa de acerto e uma simulação de investimento.

A métrica taxa de acerto representa o percentual de acerto da previsão da tendência dos preços, sendo uma medida que representa a confiabilidade do sistema. Quanto maior o percentual de acerto obtido mais promissor é o sistema previsor.

Em [9], o previsor gera um valor nominal, que representa a variação do preço. Neste trabalho, o previsor gera a tendência do preço, sendo necessária uma adapatação da fórmula original. Dessa forma, o cálculo da taxa de acerto é realizado conforme:

$$
\text { Acerto }=\frac{1}{n} \sum_{t=1}^{n} D_{t}
$$

Revista Brasileira de Computação Aplicada (ISSN 2176-6649), Passo Fundo, v. 8, n. 2, p. 113-128, jul. 2016117 


$$
D_{t}=\left\{\begin{array}{c}
1, \text { se }\left(\left(\text { valor }_{t}-\text { valor }_{t-1}\right) \geq 0 \text { e }\left[\text { obtido }_{1}, \text { obtido }_{2}\right]=[1,-1]\right) \\
1, \text { se }\left(\left(\text { valor }_{t}-\text { valor }_{t-1}\right)<0 \text { e }\left[\text { obtido }_{1}, \text { obtido }_{2}\right]=[-1,1]\right) \\
0, \text { caso contrário }
\end{array}\right.
$$

em que Acerto corresponde à taxa de acerto, $n$ equivale ao número de testes realizados, $D_{t}$ corresponde ao número de acertos na previsão da tendência, valor $t$ é o preço do ativo no dia $t$, obtido $_{1}$ e obtido $_{2}$ são os valores de saída dos neurônios da camada de saída da RNA.

A métrica simulação de investimento tem como objetivo analisar o retorno do investimento utilizando os dados reais do período testado. A simulação segue as regras: 1) comprar o maior número de ações possível de acordo com o capital disponível, caso o sistema previsor indique uma tendência de alta; 2) vender todas as ações, de posse do investidor, caso o sistema indique uma tendência de baixa.

Para que a simulação de investimento seja possível, foi necessário fixar uma regra quanto ao preço de compra e venda das ações. O preço praticado é igual ao preço de fechamento do dia atual. Na prática isso não é possível, pois após o fechamento do pregão só é possível negociar ações no dia seguinte, e o preço de abertura do dia seguinte é diferente do preço de fechamento do dia atual. Por isso, considera-se que a previsão de tendência ocorre aproximadamente 5 minutos antes do fechamento do pregão, de forma que os preços praticados naquele instante não difiram muito dos preços de fechamento e que a negociação (compra ou venda) aconteça ainda no mesmo dia.

Ao final do período analisado, é calculado o percentual de retorno com a simulação de investimento. Um percentual de $100 \%$ significa que o capital inicial foi mantido ao final do período. Percentuais maiores que $100 \%$ representam lucro e percentuais menores que $100 \%$ representam prejuízo com o investimento durante o período analisado.

\section{Metodologia}

A pesquisa teórica realizada teve como objetivo verificar, em trabalhos correlatos, a forma como o problema de previsão de séries temporais financeiras vem sendo abordada. Após esse levantamento, foi possível definir as variáveis que seriam testadas na previsão e também a técnica computacional, redes neurais artificiais, que seria implementada no sistema de previsão.

Com as variáveis definidas foi realizada a coleta dos dados de negociação das ações e dos dados exógenos. Foram utilizados os dados do período entre $1^{\circ}$ de janeiro de 2011 e 10 de março de 2014, gerando 750 amostras para treinamento e teste. O conjunto de treinamento consiste de $\frac{2}{3}$ de todos os dados, abrangendo o período que se estende de janeiro de 2011 até março de 2013, enquanto o conjunto de testes é composto pelo $\frac{1}{3}$ restante. Os dados foram coletados de duas fontes: Energy Information Administration ${ }^{2}$, do qual foi coletada a cotação a cotação do barril de petróleo Brent, os demais índicadores foram coletados na BM\&FBovespa.

Após a coleta, foram necessários alguns pré-processamentos para que os dados pudessem ser utilizados como entrada das RNAs. A cotação do barril de petróleo Brent que se apresentava em dólar foi convertida para real. Outro pré-processamento necessário foi a geração dos indicadores de análise técnica com base na série de fechamento: BB, MACD e MMS. O indicador BB foi calculado por meio de uma média móvel simples dos últimos vinte dias, gerando a banda superior e a banda inferior, formadas pelo acréscimo e decréscimo, respectivamente, de duas unidades do desvio-padrão. O indicador MACD gera três informações: a linha MACD que corresponde à diferença entre a média móvel exponencial de 12 e de 26 dias; a linha de sinal que é calculada pela média móvel exponencial de nove dias; e o histograma que é a diferença entre a linha MACD e a linha de sinal. O indicador MMS é formado por duas informações: a média móvel simples de treze dias e a média móvel simples de vinte dias. Após isso, todos os dados foram normalizados para o intervalo [-1;1], a fim de compensar as diferenças dos valores de cada dimensão do vetor de entrada [26].

Os experimentos foram divididos em três partes. Na primeira parte, o objetivo foi testar as RNAs formadas com variáveis dependentes da ação, que representam o resumo de negociação da ação em determinado dia, para verificar se essas informações isoladas são suficientes para que as RNAs determinem a direção de movimentação

\footnotetext{
${ }^{2}$ Energy Information Administration, disponível em <http://www.eia.gov/>. Órgão estatístico do governo dos Estados Unidos da América, responsável pela coleta, análise e disseminação de informações sobre energia.
}

Revista Brasileira de Computação Aplicada (ISSN 2176-6649), Passo Fundo, v. 8, n. 2, p. 113-128, jul. 2016118 
do preço das ações no dia seguinte. Então, com essas variáveis, foram testadas diversas combinações visando verificar se alguma dessas informações era irrelevante para a previsão. Da mesma forma, na segunda parte, foram testadas as RNAs com variáveis exógenas e indicadores de análise técnica, verificando se essas informações seriam suficientes para prever a movimentação do preço das ações no dia seguinte.

Por fim, foram realizados experimentos de fusão: fusão de características e fusão das saídas das redes neurais artificiais. A fusão das características foi realizada para verificar se as informações das variáveis dependentes e das variáveis exógenas e indicadores se complementariam e possibilitariam uma melhor previsão. Já a fusão das saídas das redes neurais artificiais teve como objetivo combinar as saídas das RNAs com variáveis dependentes e das RNAs com variáveis exógenas e indicadores buscando agregar as informações "aprendidas"por cada uma das RNAs para obter uma melhor previsão da movimentação do preço das ações.

\section{Experimentos}

O teste binomial para diferenças de proporção [27] é utilizado para testar se as diferenças de duas proporções binomiais são estatisticamente significantes. Quando não especificado, o nível de significância $\alpha$ é igual a 0,05 . Esse teste de significância é aplicado apenas sobre as taxas de acerto.

\subsection{RNA com variáveis dependentes}

A RNA com variáveis dependentes é caracterizada pela utilização dos valores que resumem o dia de negociação de uma ação em bolsa como dados de entrada. As variáveis dependentes e sua forma de representação estão descritas na Tabela 1, em que $t$ representa o dia atual, $x$ corresponde ao número de dias anteriores em relação ao dia atual e $y$ representa o número de dias considerado para o cálculo da diferença relativa. Os experimentos foram realizados com a utilização das variáveis dependentes em sua forma estática, em que $y=0$ e em uma forma dinâmica, obtida por meio do cálculo da diferença relativa dos últimos dias, em que $y>0$.

Tabela 1: Descrição das variáveis dependentes do ativo.

\begin{tabular}{|l|l|}
\hline Descrição & Variável de entrada \\
\hline Fechamento da ação no período $t-x$ & fechAcao $(t-x, y)$ \\
\hline Abertura da ação no período $t-x$ & abeAcao $(t-x, y)$ \\
\hline Valor máximo da ação no período $t-x$ & $\operatorname{maxAcao}(t-x, y)$ \\
\hline Valor mínimo da ação no período $t-x$ & $\operatorname{minAcao}(t-x, y)$ \\
\hline Volume negociado da ação no período $t-x$ & $\operatorname{volAcao}(t-x, y)$ \\
\hline
\end{tabular}

Fonte: elaborada pelos autores com base em dados da pesquisa.

Os experimentos são avaliados por duas métricas: taxa de acerto e percentual de retorno de uma simulação de investimento. No entanto, as taxas obtidas por essas métricas não são perfeitamente correlacionadas. O coeficiente de correlação $\rho$ foi calculado a partir de todo o conjunto de experimentos realizados. Para a ação ITUB4 $\rho=0.77$, para PETR4 $\rho=0.70$ e para VALE5 $\rho=0.68$. Isto significa que a taxa de acerto apresenta uma forte correlação com o retorno da simulação de investimento, mas como essa correlação não é perfeita $(\rho=1)$ podem ocorrer situações em que a taxa de acerto aumenta e o retorno com a simulação de investimento diminui.

\subsubsection{Variáveis de entrada estáticas}

Para fins de comparação de experimentos foi definido um modelo, denominado Base, que utiliza o vetor de características $[f e c h A c a o(t, 0), \operatorname{abe} A \operatorname{cao}(t, 0), \max A \operatorname{cao}(t, 0), \min A \operatorname{cao}(t, 0), \operatorname{vol} A \operatorname{cao}(t, 0)]$. Nota-se que essas variáveis representam todo o conjunto de variáveis dependentes, e o vetor de entrada tem uma dimensionalidade 5-D. Os resultados desse experimento apresentaram um percentual de acerto não melhor que a chance, como mostra a Figura 2. No que se refere à simulação de investimento com o modelo Base, obteve-se lucro com as 3 ações analisadas, sendo 16,4\% na ação ITUB4, 7,8\% na ação PETR4 e 18,1\% na VALE5. Isso representa um resultado satisfatório, pois a inflação acumulada para o período analisado foi de aproximadamente $6 \%$.

Revista Brasileira de Computação Aplicada (ISSN 2176-6649), Passo Fundo, v. 8, n. 2, p. 113-128, jul. 2016119 
Figura 2: Taxa de acerto e simulação de investimento dos modelos Base e Base com atraso da RNA com variáveis dependentes, utilizando dados estáticos

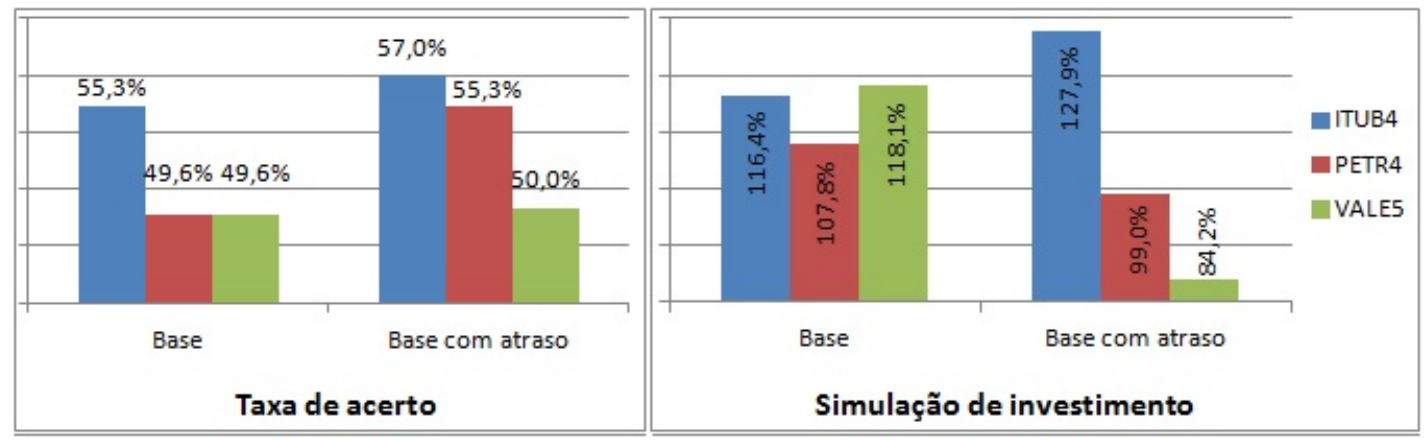

Fonte: elaborada pelos autores com base nos experimentos realizados.

No entanto, como o experimento com o modelo Base não produziu taxas de acerto estatisticamente melhores que a chance (probabilidade de acertar o resultado dentre as duas possibilidades existentes, ou seja, 50\%), dois novos modelos foram construídos isolando as variáveis do modelo Base: a série temporal de fechamento da ação $[f e c h A c a o(t, 0)]$ e as séries com as outras informações dependentes $[a b e A c a o(t, 0), \max A c a o(t, 0)$, minAcao $(t, 0)$, volAcao $(t, 0)$ ]. Esses modelos foram denominados como Fechamento, cujo vetor de entrada possui uma dimensionalidade 1-D, e Outros, cujo vetor tem uma dimensão 4-D. As RNAs construídas utilizando esses vetores como entrada não obtiveram resultados melhores. Portanto, as informações utilizadas no modelo Base se complementam e são capazes de produzir melhores resultados se utilizadas em conjunto do que se utilizadas isoladamente.

Como os modelos Fechamento e Outros não melhoraram o desempenho, e com o intuito de melhorar os resultados obtidos, criou-se um novo modelo denominado Base com atraso, que tem um vetor de entrada de dimensão 15-D, composto por todas variáveis dependentes, com a cotação do dia atual e dos dois dias úteis imediatamente anteriores. $\mathrm{O}$ vetor de entrada utilizado neste experimento pode ser expresso como

$$
\begin{array}{r}
\text { Base com atraso }=[f e c h A c a o(t-x, 0), \operatorname{abeAcao}(t-x, 0), \max A \operatorname{cao}(t-x, 0), \operatorname{minAcao}(t-x, 0), \\
\operatorname{volAcao}(t-x, 0)]
\end{array}
$$

em que $x \in[0 ; 2]$. Apesar de esse experimento produzir taxas de acerto superiores ao modelo Base, como mostra a Figura 2, essa diferença não é estatisticamente significante. Entretanto, essa diferença proporcionou um melhor retorno na simulação de investimento da ação ITUB4. O mesmo não ocorreu com as outras ações, que tiveram uma queda no percentual de retorno e apresentaram prejuízo no período analisado. Essa falta de correlação entre taxa de acerto e percentual de retorno financeiro ocorre pois, em algumas situações, acertar a tendência é mais vantajoso que em outras. Por exemplo, considerando que o investidor tenha ações para vender e que o sistema acerte a tendência de baixa antes de uma queda de $10 \%$. Esse acerto de tendência é mais vantajoso que acertar a tendência de baixa antes de uma queda de $1 \%$. Portanto, melhorar a taxa de acerto não dá garantias de melhores retornos financeiros.

Além dos citados, foram realizados diversos experimentos com dados estáticos, gerando diferentes combinações das variáveis dependentes do ativo, para servirem de entrada na RNA. Todos esses experimentos não produziram melhores resultados.

\subsubsection{Variáveis de entrada dinâmicas}

Como os experimentos realizados com as variáveis de entrada estáticas não produziram resultados melhores do que a chance, resolveu-se explorar a capacidade de generalização das RNAs por meio da utilização de dados dinâmicos. Os dados dinâmicos são caracterizados por representarem um comportamento de variação dos dados, como a diferença de valor dos $y$ últimos dias ou a taxa de variação entre o dia $x$ e o dia $y$. Neste trabalho, os dados

Revista Brasileira de Computação Aplicada (ISSN 2176-6649), Passo Fundo, v. 8, n. 2, p. 113-128, jul. 2016120 
dinâmicos foram gerados por meio do cálculo de diferença relativa entre os últimos $y$ dias. Inicialmente os dados dinâmicos foram gerados por meio do cálculo da diferença relativa dos últimos 2 dias, da seguinte forma

$$
d \operatorname{Var}(t, 2)=v \operatorname{Var}(t)-v \operatorname{Var}(t-1)
$$

em que $t$ representa o dia atual e $v V$ ar representa o valor estático da variável.

Os experimentos realizados com dados dinâmicos seguiram a mesma lógica dos experimentos realizados com dados estáticos. Inicialmente, foi definido um modelo Base da RNA com variáveis dinâmicas dependentes, utilizando o vetor de características $[f \operatorname{ech} A \operatorname{cao}(t, 2), \operatorname{abe} A c a o(t, 2), \max A c a o(t, 2), \min A c a o(t, 2)$, $\operatorname{vol} A c a o(t, 2)]$ como entrada para a rede neural, em que $t$ é o dia atual. Esse modelo produziu resultados semelhantes aos apresentados pelo modelo Base com dados estáticos, com uma taxa de acerto um pouco mais elevada mas que não é estatisticamente significante.

Para verificar o comportamento das RNAs com as variáveis isoladas, foram gerados os modelos Fechamento $[f e c h A c a o(t, 2)]$ e Outros $[a b e A c a o(t, 2), \max A \operatorname{cao}(t, 2), \min A c a o(t, 2)$ e volAcao $(t, 2)]$. Esses experimentos não produziram resultados melhores que o modelo Base. Além desses, foi criado o modelo Base com atraso, com as mesmas variáveis do modelo Base porém com dados do dia atual e dos últimos dois dias, cujo vetor de características tem uma dimensionalidade 15-D. Esse experimento mostrou-se consistente, pois todas as ações produziram resultados semelhantes, tanto para a taxa de acerto quanto para a simulação financeira calculada, porém nenhum deles apresentou um retorno financeiro muito maior do que a inflação acumulada no período.

Como os dados dinâmicos gerados pela diferença relativa de dois dias alcançaram resultados semelhantes, e em alguns casos melhores que os estáticos, resolveu-se testar o poder de generalização das RNAs com dados dinâmicos gerados por meio do cálculo da diferença relativa dos últimos 3 e 5 dias. A diferença relativa para mais de dois dias é calculada utilizando regressão polinomial ortogonal de primeira ordem na trajetória temporal da característica [28]. O coeficiente polinomial ortogonal de primeira ordem, ou a inclinação da reta generalizada, para três e cinco dias possui a seguinte forma:

$$
d \operatorname{Var}(t, 3)=v \operatorname{Var}(t) * 0.5+v \operatorname{Var}(t-1) * 0+v \operatorname{Var}(t-2) *(-0.5)
$$

e

$$
d \operatorname{Var}(t, 5)=v \operatorname{Var}(t) * 0.2+v \operatorname{Var}(t-1) * 0.1+v \operatorname{Var}(t-2) * 0+v \operatorname{Var}(t-3) *(-0.1)+v \operatorname{Var}(t-4) *(-0.2)
$$

em que $t$ representa o dia atual, $v \operatorname{Var}$ representa o valor estático da variável, $d \operatorname{Var}(t, 3)$ corresponde à diferença relativa de três dias e $d \operatorname{Var}(t, 5)$ representa a diferença relativa de cinco dias.

Dos experimentos realizados com dados dinâmicos calculados pela diferença relativa dos últimos três dias, destaca-se o modelo Base com atraso, que contém as mesmas variáveis do modelo Base com atraso anterior, porém a diferença calculada é de três dias. Esse modelo, como mostra a Figura 3, apesar de apresentar taxas de acerto menores nas três ações analisadas, possibilitou um ganho financeiro em duas dessas ações conforme simulação de investimento realizada.

Por sua vez, os experimentos realizados com a diferença relativa de cinco dias sempre apresentavam taxas inferiores em relação aos realizados com dados estáticos, dinâmicos da diferença de dois dias e dinâmicos da diferença de três dias. Com isso, pode-se concluir que a informação da diferença entre dois, ou no máximo três dias, é suficiente para o modelo classificador e que agregar a informação da diferença de mais dias não auxilia na classificação.

\subsection{RNA com variáveis exógenas e indicadores}

Os experimentos realizados na RNA com variáveis exógenas e indicadores, assim como nos realizados com a RNA com variáveis dependentes, são avaliados pelas métricas taxa de acerto e percentual de retorno obtidos por meio de uma simulação de investimento. A partir do conjunto de experimentos realizados na RNA com variáveis exógenas e indicadores, foi possível verificar que existe uma correlação moderada entre a taxa de acerto e o retorno financeiro. Os coeficientes de correlação para essa RNA foram menores, se comparados com os obtidos com os experimentos da RNA com variáveis dependentes. Para a ação ITUB4 $\rho=0.62$, para a PETR4 $\rho=0.39$ e para a VALE5 $\rho=0.49$.

Revista Brasileira de Computação Aplicada (ISSN 2176-6649), Passo Fundo, v. 8, n. 2, p. 113-128, jul. 2016121 
Figura 3: Taxa de acerto e simulação de investimento dos modelos Base com atraso da RNA com variáveis dependentes, utilizando dados dinâmicos calculados pela diferença dos últimos dois e três dias
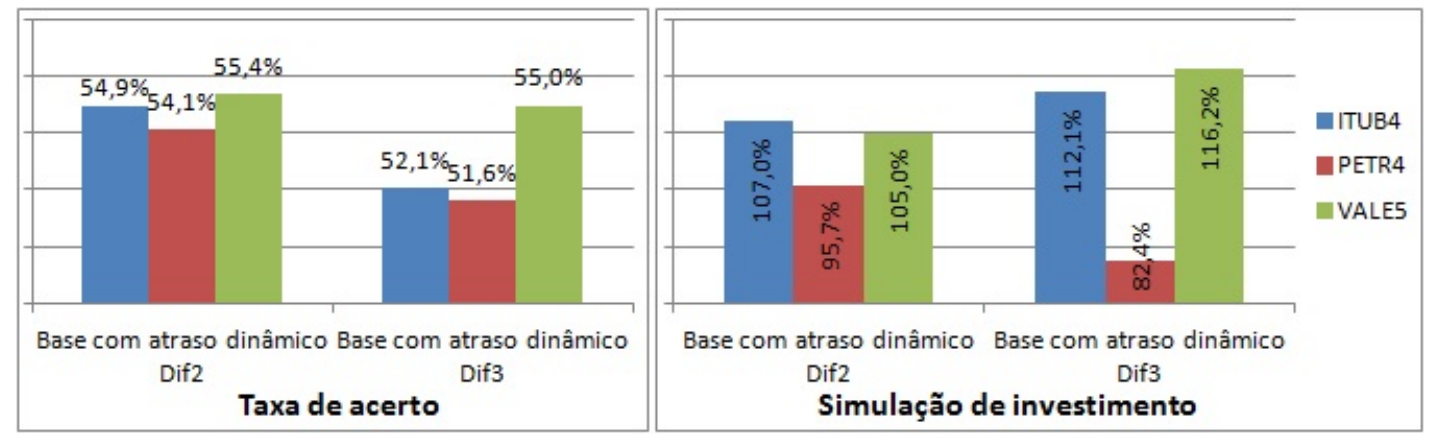

Fonte: elaborada pelos autores com base nos experimentos realizados.

A descrição das variáveis utilizadas para a realização dos experimentos com variáveis exógenas e indicadores é exibida da Tabela 2. Com a combinação desse conjunto de variáveis, foram gerados os modelos de dados de entrada da RNA. Os modelos foram gerados utilizando dados estáticos, $y=0$ e dados dinâmicos calculados pela diferença relativa de $y$ dias, onde $y>0$.

Tabela 2: Descrição das variáveis exógenas e de indicadores

\begin{tabular}{|l|l|}
\hline Descrição & Variável de entrada \\
\hline Fechamento do IBovespa no período $t-x$ & $\operatorname{ibov}(t-x, y)$ \\
\hline Fechamento do índice setorial da ação no período $t-x$ & $\operatorname{indSet}(t-x, y)$ \\
\hline Fechamento da cotação do dólar no período $t-x$ & $\operatorname{dolar}(t-x, y)$ \\
\hline Valor da linha MACD no período $t-x$ & $\operatorname{macd}(t-x, y)$ \\
\hline Valor da linha de sinal MACD no período $t-x$ & $\operatorname{macdSinal}(t-x, y)$ \\
\hline Valor do histograma MACD no período $t-x$ & $\operatorname{macdHist}(t-x, y)$ \\
\hline Valor inferior das bandas de Bollinger no período $t-x$ & $\operatorname{BBInf}(t-x, y)$ \\
\hline Valor superior das bandas de Bollinger no período $t-x$ & $\operatorname{BBSup}(t-x, y)$ \\
\hline Valor da MMS de longo prazo no período $t-x$ & $\operatorname{MMSMaior}(t-x, y)$ \\
\hline Valor da MMS de curto prazo no período $t-x$ & $\operatorname{MMSMenor~}(t-x, y)$ \\
\hline
\end{tabular}

Fonte: elaborada pelos autores com base em dados da pesquisa.

\subsubsection{Variáveis de entrada estáticas}

Seguindo a mesma lógica dos experimentos realizados na RNA com variáveis dependentes, definiu-se um modelo Base para os experimentos realizados na RNA com variáveis exógenas e indicadores. O modelo Base utiliza o vetor de características $[i b o v(t, 0)$, indSet $(t, 0), \operatorname{dolar}(t, 0), \operatorname{macd}(t, 0), \operatorname{macd} \operatorname{Sinal}(t, 0), \operatorname{macdHist}(t, 0)$, $B B I n f(t, 0)$, BBSup $(t, 0)$, MMSMaior $(t, 0)$, MMSMenor $(t, 0)]$ como entrada na RNA, em que $t$ corresponde ao dia atual.

Em seguida, foram gerados quatro modelos isolando as variáveis exógenas e indicadores. Esses modelos utilizam os seguintes vetores de características como entrada na RNA:

$$
\begin{aligned}
\text { Exogenos } & =[i \operatorname{bov}(t), \operatorname{indSet}(t), \operatorname{dolar}(t)] \\
\text { Macd } & =[\operatorname{macd}(t), \operatorname{macdSinal}(t), \operatorname{macdHist}(t)] \\
\text { Bollinger } & =[\operatorname{BBInf}(t), \operatorname{BBSup}(t)] \\
\text { CruzamentoMMS } & =[M M \operatorname{Maior}(t), \operatorname{MMSMenor}(t)]
\end{aligned}
$$

Revista Brasileira de Computação Aplicada (ISSN 2176-6649), Passo Fundo, v. 8, n. 2, p. 113-128, jul. 2016122 
As RNAs construídas com os vetores de características dos modelos Exogenos, Macd, Bollinger e Cruzamento MMS não apresentaram taxas de acerto melhores que a chance. No que se refere aos percentuais de retorno obtidos por meio da simulação com esses modelos, nenhum deles possibilitou a obtenção de lucro. O modelo Base, apesar de não apresentar taxa de acerto melhor que a chance, possibilitou a obtenção de uma taxa de retorno na simulação de investimento de $113,7 \%$ na ação ITUB4. Para as ações PETR4 e VALE5, a taxa de retorno foi menor do que $100 \%$, representando um prejuízo no investimento.

Após esses experimentos, testou-se o modelo Base com atraso para a RNA com variáveis exógenas e indicadores. Esse modelo utilizou um vetor de características com dimensionalidade 30-D, que contém o conjunto de todas as variáveis exógenas e indicadores, com os valores de cotação do dia atual e dos dois dias úteis imediatamente anteriores. Esse experimento produziu valores não superiores aos experimentos anteriores. Vários outros experimentos foram testados, combinando as variáveis exógenas e indicadores na entrada da RNA, porém nenhum apresentou um desempenho melhor. Esses outros experimentos realizados incluíram a combinação de dados de diferentes indicadores, de indicadores com variáveis exógenas e variação nos dados exógenos utilizados.

\subsubsection{Variáveis de entrada dinâmicas}

Com o objetivo de verificar o poder de generalização da RNA com variáveis exógenas e indicadores e de alcançar melhores taxas de acerto e de retorno no investimento, foram realizados experimentos com dados dinâmicos. Os dados dinâmicos para esses experimentos foram obtidos por meio do cálculo da diferença relativa de dois dias, conforme a Equação 4. Os vetores de características dos modelos testados foram definidos como:

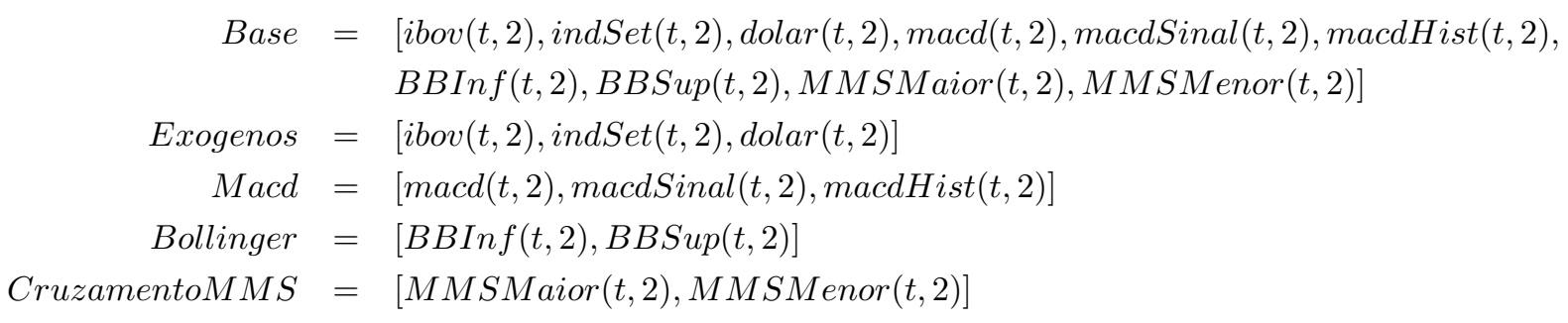

Os resultados obtidos com esses modelos não foram melhores que os resultados alcançados com dados estáticos. Portanto, para a RNA com variáveis dependentes e indicadores, dados dinâmicos calculados pela diferença relativa dos últimos dois dias apresentam um desempenho inferior se comparados com dados estáticos.

Foram testados ainda os modelos Base com atraso com dados dinâmicos, calculados pela diferença relativa de dois e de três dias. Ambos os modelos alcançaram taxas de acerto ligeiramente superiores, se comparadas as obtidas nos modelos anteriores. Os percentuais de retorno de uma simulação de investimento também alcançaram valores que implicariam em um lucro no período analisado, conforme é exibido na Figura 4.

Figura 4: Taxa de acerto e simulação de investimento dos modelos Base com da RNA com variáveis exógenas e indicadores, utilizando dados dinâmicos calculados pela diferença de dois e de três dias

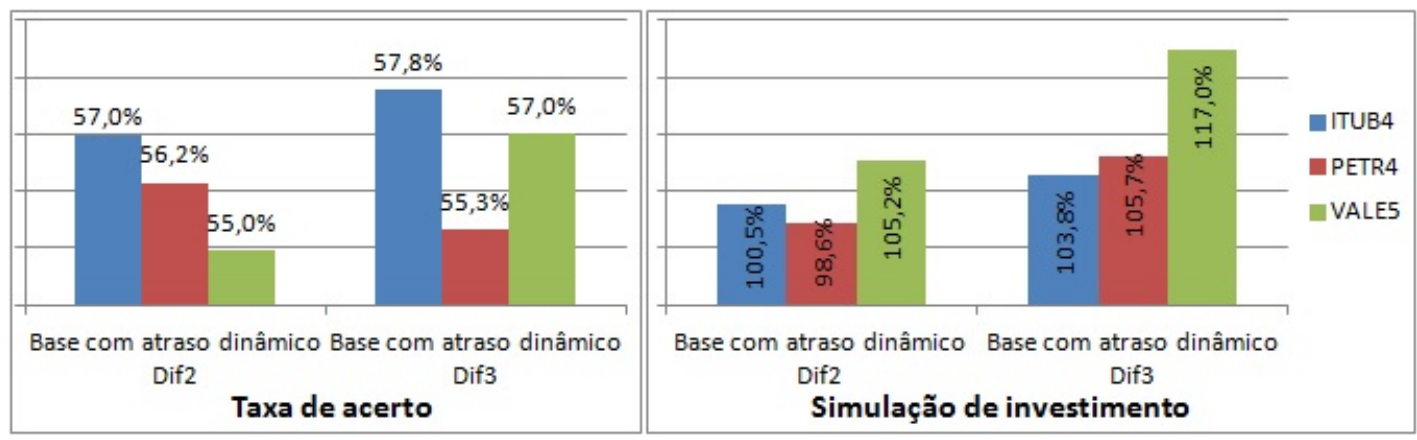

Fonte: elaborada pelos autores com base nos experimentos realizados.

Revista Brasileira de Computação Aplicada (ISSN 2176-6649), Passo Fundo, v. 8, n. 2, p. 113-128, jul. 2016123 
Além dos experimentos com os modelos citados, foram gerados outros modelos com dados dinâmicos calculados pela diferença de dois e de três dias. Também foram testados os modelos com dados formados pela diferença relativa dos últimos cinco dias. Nenhum desses experimentos apresentou melhores resultados que os já citados.

\subsection{Fusão}

Visando melhorar os resultados obtidos foram realizados alguns testes de fusão. Esses testes podem ser divididos em dois tipos quanto à natureza da fusão: fusão das características e fusão das RNAs.

\subsubsection{Fusão das características}

Com o objetivo de avaliar a complementaridade das características, experimentos foram realizados com base na fusão das variáveis de entrada das RNAs. Dois tipos de experimentos foram realizados: fusão de dados estáticos com dados dinâmicos e fusão das variáveis dependentes com as variáveis exógenas e indicadores. Os resultados mostraram que não houve um ganho significativo em ambos os experimentos. A fusão produziu vetores de entrada com dimensão maior que tornou o treinamento da RNA mais complexo. Assim, pode-se afirmar que não existe uma complementariedade nas informações dos dados de entrada, que proporcione um desempenho melhor na previsão de tendência de movimentação do preço das ações analisadas.

\subsubsection{Fusão das RNAs}

A fusão das RNAs consiste em utilizar como dados de entrada, em uma RNA de fusão, as saídas de duas outras RNAs previamente treinadas, conforme proposto na Figura 1. Dessa forma, foram realizados diversos experimentos selecionando as melhores RNAs com variáveis dependentes e RNAs com variáveis exógenas e indicadores, com o objetivo de verificar se a combinação de RNAs possibilita um ganho de performance se comparada a qualquer uma das RNAs atuando isoladamente.

Um dos experimentos de fusão de RNAs consistiu na fusão dos modelos Base com dados dinâmicos da diferença de dois dias (Figura 5). Nesse caso, os resultados apresentados por uma das RNAs que foi combinada, a RNA com variáveis exógenas e indicadores, para a ação VALE5, apontavam um prejuízo de 16,1\%. A fusão das RNAs produziu resultados melhores, reduzindo o prejuízo apresentado individualmente pela RNA com variáveis exógenas e indicadores. E quando os resultados das RNAs individuais já apresentavam lucro, como para a ação PETR4, a fusão delas possibilitou alcançar resultados ainda melhores.

Figura 5: Taxa de acerto e simulação de investimento da fusão dos modelos Base da RNA com variáveis dependentes (1) e da RNA com variáveis exógenas e indicadores (2), utilizando dados dinâmicos calculados pela diferença de dois dias

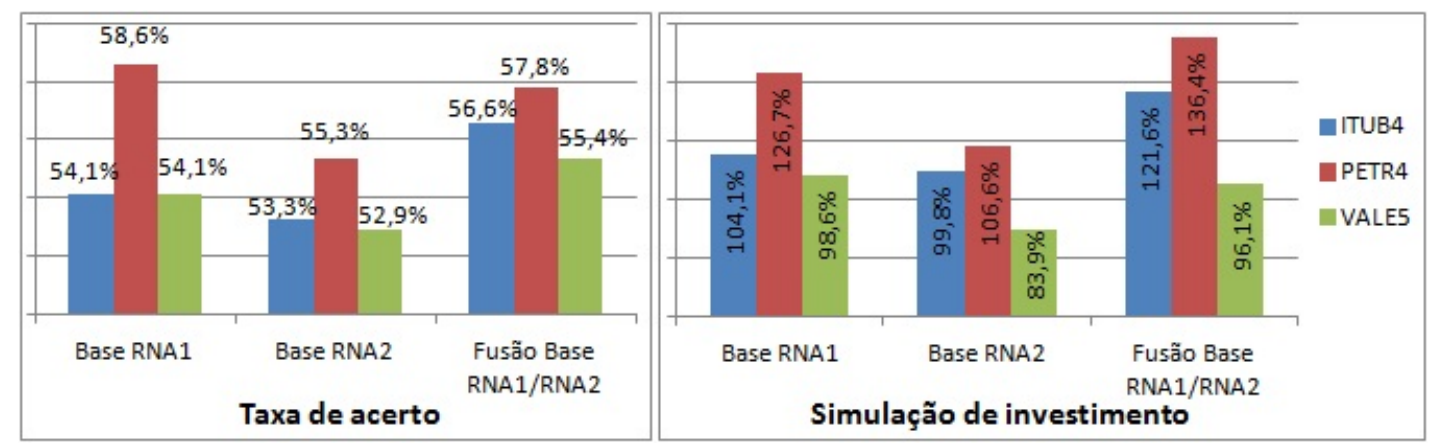

Fonte: elaborada pelos autores com base nos experimentos realizados.

Outro experimento de fusão que merece destaque é o formado pela fusão dos modelos Base com atraso, que utilizam dados dinâmicos calculados pela diferença de três dias. Este alcançou bons retornos financeiros na 
simulação de negociação das três ações analisadas, como pode ser verificado na Figura 6, possibilitando a obtenção de lucro de 13,8\%, nas ações ITUB4 e PETR4, e de 24,2\% na ação VALE5. Destaca-se que a fusão destes modelos não acarretou em um aumento da taxa de acerto, porém proporcionou maiores ganhos no investimento simulado para as três ações analisadas. Esse foi o modelo escolhido como sistema previsor final, pois se mostrou mais consistente possibilitando a obtenção de ganhos em todas as ações analisadas.

Figura 6: Taxa de acerto e simulação de investimento da fusão dos modelos Base com atraso da RNA com variáveis dependentes (1) e da RNA com variáveis exógenas e indicadores (2), utilizando dados dinâmicos da diferença de três dias
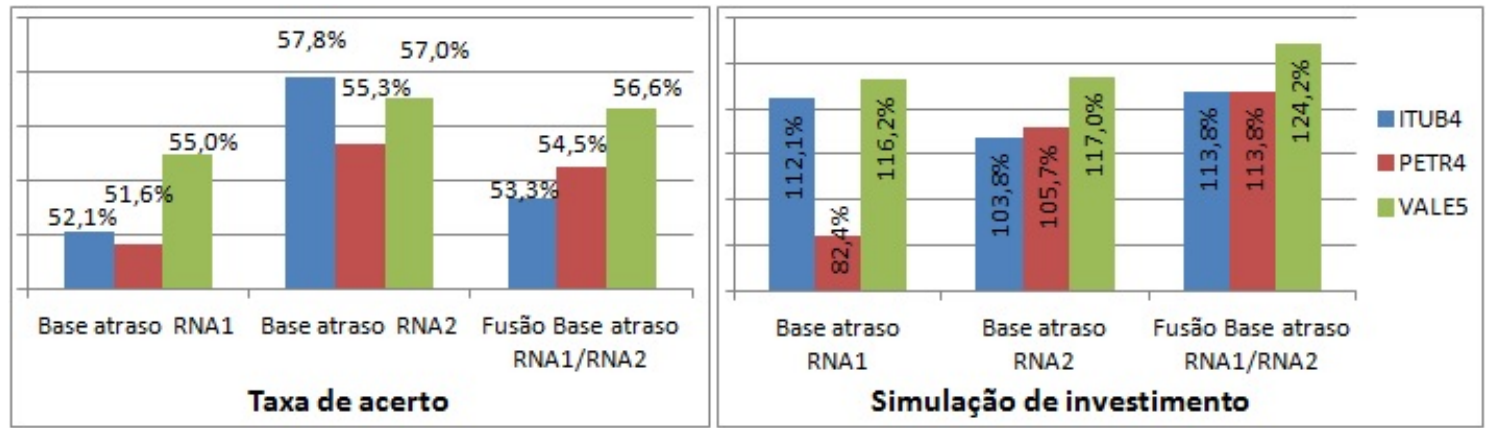

Fonte: elaborada pelos autores com base nos experimentos realizados.

Foram realizados outros experimentos de fusão de modelos das RNAs com variáveis dependentes e modelos das RNAs com variáveis exógenas e indicadores. A grande maioria dos experimentos de fusão possibilitou alcançar resultados melhores que aqueles alcançados pelas RNAs individualmente e, em situações adversas, amenizou possíveis prejuízos com uma RNA de baixo desempenho.

A fim de avaliar o desempenho do sistema previsor final, esse foi comparado com a variação real do preço das ações no período analisado e com um sistema que gera tendências aleatórias, como mostra a Figura 7 . As ações analisadas tiveram uma desvalorização real significativa no período, no qual a PETR4 teve queda de $29,6 \%$, a VALE5 teve queda de $24,8 \%$ e a ITUB4 teve queda de $16,9 \%$. Se o investidor negociasse as ações seguindo um sistema que gerasse tendências aleatórias, teria um prejuízo um pouco menor, de $14,7 \%$ na ação PETR4, de 10,1\% na ação VALE5 e de 8,1\% na ação ITUB4, segundo os valores médios obtidos após cem repetições da simulação de investimento com o sistema aleatório. Já se o investidor tivesse investido seguindo as tendências geradas pelo sistema previsor final, esse obteria lucros maiores que $13 \%$ nas três ações, sendo que na ação VALE5 alcançaria um lucro superior a $24 \%$ em um ano.

Figura 7: Variação real das ações no período analisado, simulação de investimento com tendências aleatórias e com tendências geradas pelo modelo previsor final

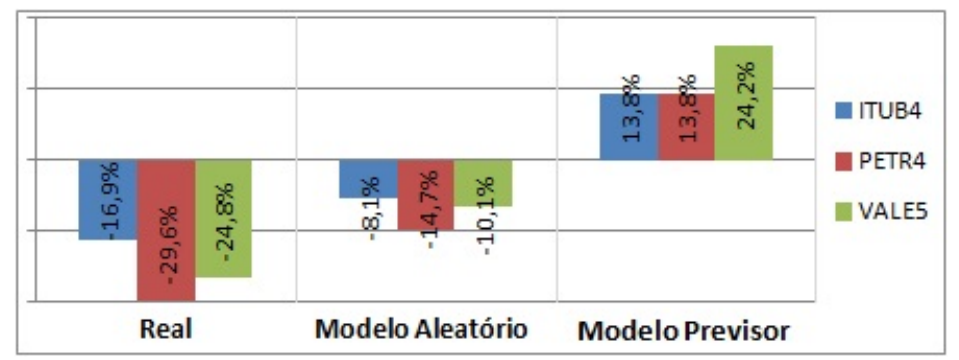

Fonte: elaborada pelos autores com base nos experimentos realizados.

Revista Brasileira de Computação Aplicada (ISSN 2176-6649), Passo Fundo, v. 8, n. 2, p. 113-128, jul. 2016125 


\section{Conclusões}

O presente trabalho teve como objetivo desenvolver uma aplicação de previsão da tendência, de alta ou baixa, nos preços de três ações do mercado brasileiro: ITUB4, PETR4 e VALE5. Para tanto, foi utilizada a técnica computacional redes neurais artificiais na concepção dos sistemas previsores. Esses sistemas utilizaram dados do mercado de ações, como resumo da negociação de ações, cotação do dólar e índices de mercado, para generalizar um padrão de comportamento de alteração do preço das ações. Primeiramente foram criados dois sistemas com dados de entrada diferentes. Após, foi realizada uma fusão desses que culminou em uma melhora dos resultados obtidos em relação a qualquer um dos sistemas atuando individualmente.

As taxas de acerto obtidas nos experimentos não foram superiores a 59\%, assim como em outros trabalhos analisados. Em [20], que desenvolveu um sistema previsor para a cotação de moedas estrangeiras, a taxa de acerto média foi de aproximadamente $57 \%$. Em [8], no qual o objeto de previsão era um índice de mercado de Xangai, a taxa de acerto foi um pouco inferior, de 56,3\%. Outros trabalhos obtiveram taxas de acerto superiores, como em [13], no qual seu modelo de previsão de um índice de mercado de Istanbul alcançou a taxa de acerto de 74,5\%. A comparação de taxas de acerto obtidas nos trabalhos pode não ser uma forma efetiva de verificar se o sistema proposto obteve um bom desempenho, pois estarão sendo comparadas diferentes séries financeiras em mercados distintos.

Então, com o objetivo de ter uma noção real do desempenho do sistema previsor proposto, foi realizada uma simulação de investimento, na qual o sistema produziu resultados satisfatórios. No período de teste, as ações tiveram uma desvalorização significativa, todas as três ações tiveram queda superior a 16\%. Mesmo com essa queda importante no preço das ações, o sistema previsor final, possibilitaria a um investidor, se esse seguisse as tendências de alta/baixa geradas pelo sistema, obter lucros superiores a $13 \%$ em cada uma das três ações. Para explicitar o quão bom foi o desempenho obtido pelo sistema previsor, foi calculada a diferença absoluta entre os percentuais obtidos com o sistema previsor e os percentuais de variação real da ação. Na ação ITUB4, a diferença absoluta entre o sistema previsor e a variação real da ação foi de 30,7\%. Na ação PETR4, a diferença absoluta foi de 43,4\% e na ação VALE5, a diferença foi ainda maior, atingindo $49 \%$. Portanto, em todas as ações, o sistema previsor alcançou percentuais bastante elevados, se comparados com a variação real da ação no período. Considerando que em momentos de alta é mais fácil obter lucros no mercado de ações e que o sistema previsor alcançou percentuais bem superiores, conclui-se que esse sistema previsor tem capacidade de gerar lucros ainda maiores em momentos mais favoráveis no mercado de ações.

A partir do presente trabalho vislumbram-se algumas possibilidades de continuidade. Uma possibilidade de continuidade é testar esse sistema com outras ações do mercado brasileiro, assim como em diferentes períodos, para verificar sua capacidade de gerar lucros. No que se refere ao conjunto de características, poderiam ser agregadas novas informações ao sistema previsor, como outros indicadores de análise técnica, indicadores de análise fundamentalista e/ou notícias relevantes ao mercado acionário, de modo que essas informações poderiam auxiliar no processo de previsão de tendências.

\section{Referências}

[1] FORTUNA, E. Mercado Financeiro: produtos e serviços. 18. ed. Rio de Janeiro: Qualitymark, 2011.

[2] MURPHY, J. J. Technical analysis of the financial markets: a comprehensive guide to trading methods and applications. [S.1.]: Penguin, 1999.

[3] THEODORIDIS, S.; KOUTROUMBAS, K. Pattern recognition. 2. ed. San Diego: Elsevier, 2003.

[4] DOUGHERTY, G. Pattern recognition and classification. Camarillo: Springer, 2013.

[5] FUKUNAGA, K. Introduction to statistical pattern recognition. 2. ed. San Diego: Academic Press, 1990.

[6] TAY, F. E.; CAO, L. Application of support vector machines in financial time series forecasting. Omega, Elsevier, v. 29, n. 4, p. 309-317, 2001.

Revista Brasileira de Computação Aplicada (ISSN 2176-6649), Passo Fundo, v. 8, n. 2, p. 113-128, jul. 2016126 
[7] CHARKHA, P. R. Stock price prediction and trend prediction using neural networks. In: INTERNATIONAL CONFERENCE ON EMERGING TRENDS IN ENGINEERING AND TECHNOLOGY, 1,. Proceedings of First International Conference on. [S.1.]: IEEE, 2008. p. 592-594.

[8] ZHANG, D.; JIANG, Q.; LI, X. Application of neural networks in financial data mining. International Journal of Computational Intelligence, Fujian, v. 1, n. 2, p. 116-119, 2004.

[9] LI, R.-J.; XIONG, Z.-B. Forecasting stock market with fuzzy neural networks. In: INTERNATIONAL CONFERENCE OF MACHINE LEARNING AND CYBERNETICS 2005. Proceedings of 2005 International Conference on. [S.1.]: IEEE, 2005. v. 6, p. 3475-3479.

[10] MACEDO, J. et al. An intelligent decision support system to investment in the stock market. Latin America Transactions, IEEE, Alfenas, v. 11, n. 2, p. 812-819, 2013.

[11] NETO, M. C. A.; CALVALCANTI, G. D.; REN, T. I. Financial time series prediction using exogenous series and combined neural networks. In: INTERNATIONAL JOINT CONFERENCE ON NEURAL NETWORKS 2009. Proceedings of International Joint Conference on. [S.1.]: IEEE, 2009. p. 149-156.

[12] ABRAHAM, A.; PHILIP, N. S.; SARATCHANDRAN, P. Modeling chaotic behavior of stock indices using intelligent paradigms. International Journal of Neural, Parallel \& Scientific Computations, [S. 1.], v. 11, p. 143-160, 2003.

[13] YILDIZ, B.; YALAMA, A.; COSKUN, M. Forecasting the istanbul stock exchange national 100 index using an artificial neural network. World Academy of Science, Engineering and Technology, v. 46, p. 36-39, 2008.

[14] WU, J.-Y.; LU, C.-J. Computational intelligence approaches for stock price forecasting. In: INTERNATIONAL SYMPOSIUM ON COMPUTER, CONSUMER ANS CONTROL. Proceedings of 2012 International Symposium on. [S.1.]: IEEE, 2012. p. 52-55.

[15] NAEINI, M. P.; TAREMIAN, H.; HASHEMI, H. B. Stock market value prediction using neural networks. In: INTERNATIONAL CONFERENCE ON COMPUTER INFORMATION SYSTEMS AND INDUSTRIAL MANAGEMENT APPLICATIONS. Proceedings of 2010 International Conference on. [S.1.]: IEEE, 2010. p. 132-136.

[16] KHAN, A. U.; BANDOPADHYAYA, T.; SHARMA, S. Comparisons of stock rates prediction accuracy using different technical indicators with backpropagation neural network and genetic algorithm based backpropagation neural network. In: INTERNATIONAL CONFERENCE ON EMERGING TRENDS IN ENGINEERING AND TECHNOLOGY. Proceedings of First International Conference on. [S.1.]: IEEE, 2008. p. $575-580$.

[17] WEBB, A. R. Statistical Pattern Recognition. 2. ed. Chichester: John Wiley \& Sons, 2002.

[18] MAGER, J.; PAASCHE, U.; SICK, B. Forecasting financial time series with support vector machines based on dynamic kernels. In: IEEE CONFERENCE ON SOFT COMPUTING IN INDUSTRIAL APLLICATIONS. Proceedings of SMCia'08 Conference on. [S.1.]: IEEE, 2008. p. 252-257.

[19] VIDOTTO, R. S.; MIGLIATO, A. L. T.; ZAMBON, A. C. O moving average convergence-divergence como ferramenta paraa decisão de investimentos no mercado de ações. Revista de Administração Contemporânea, Associação Nacional de Pós-Graduação e Pesquisa em Administração, v. 13, n. 2, p. 291, 2009.

[20] BAHRAMY, F.; CRONE, S. F. Forecasting foreign exchange rates using support vector regression. In: IEEE CONFERENCE ON COMPUTACIONAL INTELLIGENCE FOR FINANCIAL ENGINEERING \& ECONOMICS. Proceedings of 2013 IEEE Conference on. [S.1.]: IEEE, 2013. p. 34-41.

[21] RIBEIRO, C.; GOLDSCHMIDT, R.; CHOREN, R. Métodos para previsão de séries temporais e suas tendências de desenvolvimento. Monografia em Sistemas e Computação - Instituto Militar de Engenharia, Rio de Janeiro, 2009.

Revista Brasileira de Computação Aplicada (ISSN 2176-6649), Passo Fundo, v. 8, n. 2, p. 113-128, jul. 2016127 
[22] VUI, C. S. et al. A review of stock market prediction with artificial neural network (ann). In: IEEE INTERNATIONAL CONFERENCE ON CONTROL SYSTEM, COMPUTING AND ENGENEERING. Proceedings of 2013 IEEE International Conference on. [S.1.]: IEEE, 2013. p. 477-482.

[23] HAYKIN, S. Redes Neurais: princípios e prática. Porto Alegre: Bookman, 2001.

[24] LUGER, G. F. Inteligência artificial. São Paulo: Pearson Education do Brasil, 2013.

[25] HORNIK, K.; STINCHCOMBE, M.; WHITE, H. Multilayer feedforward networks are universal approximators. Neural networks, San Diego, v. 2, n. 5, p. 359-366, 1989.

[26] BISHOP, C. M. Neural networks for pattern recognition. [S.1.]: Oxford university press, 1995.

[27] MOTTA, V. T. da. Bioestatística. 2. ed. Caxias do Sul: EDUCS, 2006. 190 p.

[28] SOONG, F. K.; ROSENBERG, A. E. On the use of instantaneous and transitional spectral information in speaker recognition. IEEE Transactions on Acoustics, Speech, and Signal Processing, IEEE, v. 36, n. 6, p. 871-879, 1988. 